\title{
Alejandro Malaspina, un ilustrado español en la costa norte del Pacífico (1791)*
}

\author{
EMILIO SOLER PASCUAL
}

\section{LA PRESENCIA ESPAÑOLA EN LA COSTA NOROESTE DEL PACIFICO DURANTE EL REINADO DE CARLOS III}

Las expediciones marítimas realizadas en la época de Carlos III tuvieron consecuencias muy importantes para el Imperio español. En primer lugar, llevaron hasta el Nuevo Mundo a un notable número de guardiamarinas y pilotos que pudieron poner en práctica las reformas introducidas y aprendidas durante sus estudios (1). La creación de dos apostaderos, el de San Blas (1768) y el de Montevideo (1776), dirigidos a potenciar la presencia de la Marina española en dos regiones -el Pacífico Norte y el Atlántico Sur- favorecieron también la presencia hispana en la zona que tuvieron, además, una gran importancia en la puesta en funcionamiento de las defensas americanas. Estas labores de fortificación fueron debidas a los ataques navales que sufrieron algunos de los puntos más estratégicos del sistema colonial español.

Los ataques a Pensacola, Santiago de Cuba, Trinidad, San Juan de Puerto Rico, Santo Domingo, Cartagena de Indias, Malvinas, Sacramento y Buenos Aires, son ejemplos concretos de lo necesario de este nuevo sistema defensivo. Había, pues, que proteger las costas y que adquirieran pronto estos núcleos marítimos aspecto de defensas artilladas, tanto más necesarias si comparamos el potencial marítimo español con el potencial marítimo inglés, unas 400 embarcaciones frente a 7.000 .

(*) Este texto corresponde a la conferencia dictada en la University of Chicago, Department of Romance Languages and Literatures el 25 de enero de 1991.

(1) HIGUERAS RODRIGUEZ, M. ${ }^{a}$ Dolores, "Desarrollo de la Armada Española en el siglo XVIII; Institucionalización de las Ciencias Náuticas", en: Revista de Historia Naval. Madrid, 1988. 
Con el fin de levantar fortalezas costeras o preparar planes bélicos se reconocieron de forma meticulosa grandes sectores del litoral americano, levantándose cartas de notable perfección (2).

La primera atención militar era la defensa de las Indias. Así pues, continuó la obra colosal de fortificar los puntos más vitales y más amenazados: San Agustín, en la frontera de Florida con las colonias inglesas de Norteamérica; La Habana; Cartagena de Indias... Todavía hoy estas fortalezas resultan imponentes y testimonian el esfuerzo que requirió su construcción (3).

En segundo lugar, las expediciones marítimas contribuyeron de forma decisiva al reconocimiento e incorporación a la monarquía de nuevos territorios. Durante el reinado de Carlos III los dominios españoles en América alcanzaron su máxima extensión. El Noroeste de América fue la última zona templada incorporada a la expansión occidental. Gracias a la Armada, se realizó la colonización de la Alta California -fijando en Nutka los límites septentrionales del Imperio-, se inició el poblamiento de la Patagonia y de las Islas Malvinas, y se ensayó la ocupación de Tahití. Si a esto le sumamos las incorporaciones territoriales debidas a los acontecimientos bélicos -políticos (Paz de París, Tratado de San Ildefonso o Paz de Versalles) podemos deducir que el reinado de Carlos III puede considerarse como el del apogeo de la presencia y acción de España en el Nuevo Mundo (4).

Un aspecto importante a considerar en esa expansión y colonización española en América podría ser la labor de los misioneros, que no solamente eran agentes de la evangelización, sino de españolización; gracias a ellos territorios muy extensos y tribus muy poderosas se incorporaron sin gastos ni violencias al conjunto imperial.

Los monjes franciscanos conquistaron para España un nuevo dominio. El Padre Junípero Serra, su superior, quería crear en el norte de California una gran colonia española en la que la población se debería componer, únicamente, de indios convertidos; una carretera debía unir los dos puntos extremos de la colonia y estaría jalonada por siete misiones (5). El plan del P. Serra recibió la sanción real en

(2) FIREMAN, J: The Spanish Royal Corps of Engineers in the Western Borderlands. Instrument of Bourbon Reform 1764 to 1815. York, 1977.

(3) DOMINGUEZ ORTIZ, Antonio: Carlos III y la España de la Ilustración. Madrid, 1988.

(4) BERNABEU ALBERT, Salvador. "Las Expediciones Hidrográficas", en SELLES, PESET y LAFUENTE (ed.): Carlos III y la Ciencia de la Ilustración. Madrid, 1988.

(5) CUMMING, W.P., HILLIER, S.E., QUINN, D.B. y WILLIAMS, G.: The exploration of Nortb America, 1630-1776. New York, 1974. 
1761. A pesar de las pocas inteligentes medidas adoptadas para el desarrollo de las misiones, los españoles se expandieron rápidamente y ya, en 1792, el inglés Vancouver descubrió que éstos llevaban varios años establecidos en las orillas del estrecho de Juan de Fuca y en la isla Nutka, a $49^{\circ} \cdot 40^{\prime}$ de latitud norte (6).

Por esos mismos años se realizaron los viajes del piloto Francisco Machado a los archipiélagos occidentales (1768-1769) -alcanzando los $49^{\circ} 2^{\prime \prime}-$ y del teniente de artillería José Ruiz a vigilar la presencia de barcos ingleses y, sobre todo, a controlar la expansión rusa por el Pacífico Septentrional (7). La presencia de los españoles en las costas del Noroeste comenzó tras la expulsión de los jesuitas en 1767, continuando los trabajos de exploración iniciados en 1532 por las expediciones de Huarte de Mendoza, las de Ulloa (1539-1540), Juan Rodríguez Cabrillo (1542-1543) y Sebastián Vizcaíno (1602) (8).

Durante el reinado de Carlos III se realizó la colonización de la Alta California y la exploración del Pacífico septentrional hasta la lejana Alaska, para lo cual se fundaría previamente (en 1767) un departamento marítimo en San Blas (Nueva Galicia) (9). El impulsor de esta gran expansión norteña fue el visitador de Nueva España, José de Gálvez (10), quien en 1768 organizó minuciosamente una doble expe-

(6) DESDEVISES DU DEZERT, Georges: La España del Antiguo Régimen. Madrid, 1989.

(7) DMYTRYSHYN, Basil; CROWNHART-VAUGHAN, E.A.P. y VAUGHAN, Thomas: Russian penetration on the North Pacific Ocean. A documentary record, 17001797. Oregon, Historical Society Press, 1988.

(8) PORTILLO, Alvaro de: Descubrimientos y exploraciones en las costas de California, 1532-1650. Ed. Rialp. Madrid, 1982.

(9) THURMAN, Michael E.: The Naval Department of San Blas. New Spain's bastion for Alta Califormia and Nootka. Glendale, 1967.

(10) GALVEz, José de (Málaga, 1720-Aranjuez, 1787). Estudió Derecho en las Universidades de Salamanca y Alcalá. Fue abogado de la embajada francesa y secretario de Grimaldi, el ministro de Estado de Carlos III. Era alcalde de casa y corte cuando fue nombrado visitador de Nueva España con la misión especial de vigilar la actuación del virrey, el marqués de Cruillas, de cuya administración desconfiaba el Gobierno por las escasas rentas llegadas a España. Durante su visita fue nombrado ministro togado del Consejo de Indias. Sus amplias facultades dejaban a Gálvez completa independencia, debiéndose a él notables mejoras de todos los ramos pertenecientes a la Real Hacienda, no sin que se produjeran protestas por algunas medidas, como el establecimiento del estanco de tabacos. Implantó nuevos impuestos, sobre el pulque y las harinas; combatió con energía el contrabando y reformó el corrompido sistema de la aduana de Veracruz y después hizo lo mismo en Acapulco; su Instrucción de 1767 referente a la primera fue impugnada por el Consulado, pero le apoyaron el Gobierno y la opinión favorable de los entonces fiscales Floridablanca y Campomanes. Con sus refor- 
dición terrestre y marítima que lograría fundar las dos primeras misiones en la Nueva California: San Diego (1769) y Monterrey (1770). Poco después se alcanzaría el puerto de San Francisco, que fue explorado en 1775 por el teniente de navío Juan Manuel de Ayala (11).

Al mismo tiempo, varias expediciones fueron enviadas a las costas del Canadá y Alaska con el fin de localizar los establecimientos rusos denunciados por la embajada española en San Petersburgo. Diversos embajadores españoles, como el vizconde de las Herrerías o el conde de Lacy, recibieron el encargo de la Corte de "...que con la mayor maña y disimulo tratéis de indagar a qué términos han llegado los descubrimientos de los rusos en las tentativas de su navegación a la California..." (12).

En 1774, el mallorquín Juan Pérez (13), enviado por Antonio Bucarelli (14), virrey de México, inauguró con la fragata "Santiago" dichas expediciones, alcanzando tierra cerca de los $54^{\circ}$ norte -territorio que bautizó con el nombre de Santa Cristina-, y tras llegar a los $55^{\circ} 49^{\prime} \mathrm{N}$.

mas fiscales y hacendísticas, Gálvez contribuyó a financiar no sólo los gastos de México, acrecidos por las cargas militares, sino las empresas de Carlos III, gracias al vigor y la eficacia de sus métodos. Fue el encargado de la expulsión de los jesuitas en su demarcación y tuvo que afrontar diversos levantamientos por esta causa. En 1775, y recién llegado a España, fue nombrado por Carlos III, entre otras muchas cosas, Ministro Universal de las Indias, desde donde fomentó el comercio de las colonias, concediendo a bastantes puertos el privilegio que hasta entonces sólo tenía Cádiz. Fue un firme defensor del apoyo español a la guerra de Independencia norteamericana.

Vid. PRIESTLEY, Herbert: José de Gálvez, visitor general of New Spain. Berkeley, 1916.

(11) COOK, Warren: Flood Tide of Empire: Spain and the Pacific Nortbwest, 15431819. New Haven and London, Yale University Press, 1973.

(12) VILA VILAR, Enriqueta: Los rusos en América. Escuela de Estudios Hispanoamericanos. Sevilla, 1966.

(13) BERNABEU, Salvador. Juan Pérez, navegante y descubridor de las Californias (1768-1775), en Culturas de la Costa Noroeste de América. Ed. de PESET, José Luis. Ed. Turner. Madrid, 1989.

(14) BUCARELLI y URSUA, Antonio María (Sevilla, 1717-Mexico, 1779). Hijo de los marqueses de Vallehermoso. Caballero de la Orden de San Juan. Hermano de militares, él mismo fue ascendiendo puestos en el escalafón hasta que en 1757 fue comandante de caballería y participó en la invasión de Portugal; luego ascendió a mariscal de Campo e inspector general de Caballería. En 1766 es nombrado capitán general de Cuba, donde construye los fuertes del Morro y de Atarés. De Cuba pasó a Nueva España, como virrey (1771). Allí, hizo frente a las sublevaciones de los indios apaches, seris y pimas; hizo explorar el camino a Monterrey promovió la exploración de la costa norte del Pacífico y fomentó el nuevo departamento marítimo de San Blas. Gozó de la total confianza del monarca Carlos III. 
emprendió el regreso, visitando el 8 de agosto el fondeadero de Nutka (isla de Vancouver) -que bautizó como puerto de San Lorenzo-, anclando en el departamento de San Blas el 3 de noviembre (15).

No habiendo llegado a los $60^{\circ}$ N., mandó el Virrey otra expedición, en 1775, un año después, realizándose el segundo viaje de exploración, compuesto por la fragata "Santiago", al mando del teniente de navío Bruno de Heceta, y de la goleta "Sonora", gobernada por el de igual graduación, Juan Francisco de la Bodega y Cuadra. Partieron de San Blas el 16 de marzo de 1755, con víveres para un año; y en julio llegaron al estrecho de Fuca (16) tras hallar la entrada de Heceta (boca del río Columbia). Bodega y Cuadra (17), en solitario, prosiguió el viaje hasta los $58^{\circ} \mathrm{N}$. (Alaska), arribando a los puertos de Guadalupe y Los Remedios. Al regreso descubrió el puerto de Bucarelli, en homenaje al virrey de México (isla del Príncipe de Gales) y la bahía de Bodega (al norte de San Francisco) (18).

Cuatro años más tarde, en 1779 , se realizó la tercera exploración, para lo cual fueron elegidas las fragatas "Princesa" y "Favorita", esta última recientemente adquirida en El Callao. El teniente de navío Ignacio Arteaga y Juan Francisco de la Bodega y Cuadra fueron los

(15) BEALS, Herbert K.: Juan Pérez on the Nortbwest Coast. Portland, Oregon Historical Society Press, 1989.

(16) JUAN DE FUCA. Marino griego que estuvo, durante el siglo XVI, al servicio de España y que pretendió haber descubierto un paso del Pacífico al Atlántico en el noroeste de América. A fines del siglo XVIII investigaciones históricas de Navarrete y exploraciones de Vancouver y del marino español Francisco Elisa (1790-91), demostraron la falsedad del paso, y que el estrecho al que ya se llamaba -y se llama hoy- de Juan de Fuca, no es más que el brazo de mar que separa la isla de Vancouver, por el sur, de la costa del continente-actualmente del Estado norteamericano de Washington- y da acceso al Puget Sound y al estrecho de Georgia, sin que hubiera podido nunca considerarse como paso al Atlántico.

El viaje de Fuca es, por tanto, dudoso y aun juzgado como falso, y de haber existido se habría limitado al referido estrecho que ha conservado su nombre, en cuyo caso habría sido el más septentrional de los viajes realizados en el siglo XVI por la costa de California.

Vid. NOVO Y COLSON, Pedro de: Sobre los viajes apócrifos de Juan de Fuca y de Lorenzo Ferrer Maldonado. Madrid, 1881.

Vid. WAGNER, Henry Raup: Spanish Explorations in the Strait of Jian de Fuca. New York, 1971.

(17) BODEGA y QUADRA, Juan Francisco de la: El descubrimiento del fin del mundo. 1775-1792. Ed. de Salvador Bernabéu. Alianza Ed. Madrid, 1990.

(18) BERNABEU, Salvador: Viajes maritimos y expediciones científicas al Pacífico Septentrional. Universidad Complutense, Departamento de Historia de América. 6 vls. Madrid, 1989 
comandantes de esta nueva expedición, que exploró la bahía de Bucarelli, la isla del Carmen y el puerto de Santiago, lográndose alcanzar los $59^{\circ}$ N., y en donde encontraron una ensenada que llamaron de Nuestra Señora de Regla. Llegaron a la costa meridional de Alaska (19), al Prince William Sound, más al oeste del monte San Elías, a $61^{\circ}$ N., adonde no habían llegado navegantes españoles aún, pero sí los rusos, desde Siberia, y el capitán inglés James Cook (20).

La información transmitida por el marino francés La Pérouse (21) sobre extraños movimientos en las factorías rusas, hizo partir a otra expedición el 8 de marzo de 1788, formada por los navíos "Princesa" y "San Carlos", bajo las órdenes del alférez Esteban José Martínez y del piloto Gonzalo López de Haro. La expedición se dirigió directamente a los $59^{\circ}$ N., explorándose la costa hacia el Oeste hasta encontrar los establecimientos rusos (22) enterándose allí que éstos proyectaban establecerse en Nutka, por lo que el virrey Manuel Antonio Flórez (23) ordenó a Martínez y a López de Haro que ocuparan previamente este establecimiento con los mismos barcos, lo que efectuaron en 1789 tomando posesión del mismo en nombre de la Corona española. Poco tiempo después, llegaron varios buques ingleses con la misma pretensión y en la escaramuza consiguiente Martínez lo impidió y arrestó a los componentes de dos barcos. Ante este incidente, Bodega fue nombrado comandante de San Blas, enviándose a Nutka a Francisco Elisa y Salvador Fidalgo, en 1790, a hacerse cargo de la guarnición.

Los sucesos anteriores estuvieron a punto de hacer estallar un conflicto entre España e Inglaterra por la cuestión de Nutka; se resolvió gracias al Tratado de El Escorial (28 de octubre de 1790), por el que se entregó el territorio a la Gran Bretaña, fijando España el límite norte de sus posesiones en $\operatorname{los} 48^{\circ} \mathrm{N}$., con lo que renunciaba a los derechos

(19) MENCHACA, Antonio: De California a Alaska. Vida y descubrimientos de don Juan Francisco de la Bodega-Quadra. Instituto de Cooperación Iberoamericana. Madrid, 1989.

(20) COOK, James: A Voyage to the Pacific Ocean. 3 vls. and atlas. London, 1784.

(21) LA PEROUSE, Jean François Galaup, Conde de: $A$ Voyage around the world in the Years 1785,1787 and 1788.3 vls. London, J. Johnson, 1799.

(22) BARRAS DE ARAGON, Francisco de las: "Los rusos en el Noroeste de América". Anales de la Asociación Española para el progreso de las ciencias. Vol. 31. Madrid, 1956.

(23) FLOREZ Y ANGULO, Manuel Antonio (Sevilla, 1723-Madrid, 1799). Marino. Gobierna como virrey de Nueva Granada desde 1776 a 1782. En 1787, Flórez pasó al virreinato de México, sucediendo al virrey interino Núñez de Haro. Por su avanzada edad y por el clima, renunció, cesando el 17 de octubre de 1789. 
sostenidos hasta entonces sobre la costa noroeste de América. España había tenido que ceder, al no recibir apoyo de Francia que estaba inmersa en su revolución, ante el poderío naval inglés.

La conciliadora actitud de Floridablanca en el asunto de Nutka estaba provocada por la necesidad de que Europa estuviese libre de conflictos ante el hecho de la Revolución Francesa (24).

Para cumplir el Tratado partieron hacia Nutka el británico Vancouver (25) y el español Bodega (26) adonde también llegaron en viaje de reconocimiento, las goletas "Sutil" y "Mexicana", mandadas por Dionisio Galiano y Cayetano Valdés, oficiales de la expedición de Alejandro Malaspina (27) que formaban parte de la élite de la Marina

(24) GIL NOVALES, Alberto, FERNANDEZ DE PINEDO, Emiliano y DEROZIER, Albert: Centralismo, Ilustración y Agonía del Antiguo Régimen (1715-1833). Barcelona, 1988. pp. 252-253. Tomo VII de la Histotia de España dirigida por TUÑON DE LARA, Manuel.

(25) VANCOUVER, George. Explorador británico (1757-1798). Da su nombre a la isla de Vancouver, sudoeste de Canadá, de $28.413 \mathrm{Km}$. cuadrados de extensión.

(26) BODEGA y CUADRA, Juan Francisco de la. (Lima, 1743-San Blas, 1794). Marino, de noble familia vizcaína, fue caballero de Santiago. Ingresó como guardiamarina en 1762 y ascendió hasta capitán de navío en 1784 .

(27) MALASPINA, Alejandro (Mulazzo, 1754-Pontremoli, 1810). Hijo del marqués de Mulazzo. Su madre, Caterina Melilupi, era sobrina de Fogliani, que desempeñó los cargos de Ministro y de Virrey en Sicilia del futuro Carlos III. A los 18 años, Malaspina sentó plaza de guardiamarina en Cádiz y obtuvo, en 1774, la encomienda de la Orden de San Juan de Malta. Hombre ilustre e ilustrado, hablaba cinco idiomas. Pronto se distinguió en su carrera de marino y desde 1782 a 1784, ya con el grado de capitán de fragata, mandó la "Asunción", con la que realizó un largo viaje a Filipinas. Entre 1786 y 1788 realizó la circunnavegación del globo con la fragata "Astrea", periplo de más de dos años de duración y que le convirtió en el decimotercer marino que conseguía dar la vuelta al mundo.

Ya en 1788, ascendido a capitán de navió, presentó al entonces ministro de Marina, Antonio Valdés, un proyecto de expedición científico-política que trataba de aplicar la experiencia del reconocimiento de los dominios españoles en América, para su mejor gobierno, con la introducción de las reformas políticas y económicas oportunas. El proyecto de Malaspina contó también con el imprescindible apoyo del conde de Floridablanca ya que la política exterior española se había convertido en una de las bazas del reformismo carolino. En los manuscritos de Malaspina, preparatorios del viaje, se pone de relieve la admiración del marino por el pragmatismo del sistema colonial inglés y evidencia la necesidad de impulsar un modelo de gobierno liberalizador: el viejo sistema de dominación imperialista debía dejar paso a uno nuevo que basara su actividad directriz mediante el control religioso y el dominio de unos pocos, pero estratégicos, enclaves territoriales y permaneciendo el resto bajo el gobierno de las poblaciones aborígenes. Desde el punto de vista geoestratégico, uno de los principales objetivos del viaje era el estudio de la reorganización que se había producido en el tráfico marítimo del Pacífico. A la presión ejercida por Inglaterra y Francia se había unido la tendencia expansiva de los rusos que, con sus asentamientos, amenazaban la sobera- 
Española del siglo dieciocho (28); al no lograr ponerse de acuerdo Vancouver y Bodega por exigir el inglés que el límite de las posesiones èspañolas no pasara de San Francisco de California, se suspendió la delimitación. Vancouver reconoció el estrecho de Georgia entre el continente y la isla que recibió su nombre y el de Cuadra, en honor de ambos marinos, habiendo sólo prevalecido el primero de esos nombres.

nía española en las costas del norte de América, de ahí que el proyecto contemplase la necesidad de revisar las rutas comerciales y, sobre todo, de tener un mejor conocimiento del territorio, para lo que sería imprescindible el perfeccionamiento de la cartografía costera. No menos importante aparecía para el Gobierno español la utilidad de realizar un profundo estudio de la realidad político-económica de los virreinatos americanos, dirigido tanto a la reorganización del sistema de comercio intercolonial, cuanto a la averiguación de los nuevos recursos económicos que pudieran potenciar el tráfico comercial con la metrópoli.

La expedición, en la que enroló la flor y nata de la marina española del XVIII, partió, a bordo de las corbetas "Descubierta" y "Atrevida" el 30 de julio de 1789 desde el puerto de Cádiz. Recorrió el Río de la Plata, la costa de la Patagonia, las Islas Malvinas, la Tierra de Fuego, Chile, Perú, Ecuador, Panamá, Nicaragua, Méjico, California, Estados Unidos, Alaska, Canadá, las Islas Marianas y Filipinas, Australia y Tonga. Culminó con su arribada a Cádiz el 21 de septiembre de 1794. La Corte y la Corona saludó la llegada de Malaspina al que nombraron Brigadier de la Armada. La amplitud de las tareas científicas abordadas por la expedición causó auténtico sombro: Astronomía, Hidrografía, Botánica, Zoología, Mineralogía, Edafología comparada, Minería y técnicas mineras, Sociología, Demografia, Etnología, Lingüística, Historia prehispánica, Farmacopea, Salubridad ambiental, recursos vivos, caminos y comunicaciones, Numismática, Urbanismo, imposiciones fiscales, tráfico marítimo y aduanas, construcción naval, recursos pesqueros, fortificaciones y defensa, universidades, hospitales, censos eclesiásticos, además de un exhaustivo estudio fisicogeográfico, la plasmación gráfica y artística de ciudades, animales, plantas y tipos humanos de cuantos lugares visitaron, formaban parte de las amplias labores desarrolladas por la expedición.

Las difíciles circunstancias políticas de la época (reinado de Carlos IV, Revolución Francesa y ascenso al poder de Godoy) junto a las pretensiones politicas de Malaspina, que se considera minusvalorado, convierten al ilustre brigadier de la Real Armada en víctima propiciatoria para la afirmación de la autoridad del Príncipe de la Paz. Así, Malaspina intelectual de sólida formación, buen marino pero mal político, fracasa en su intento conspiratorio contra Godoy y merced a un juicio sumarísimo es condenado a 10 años de prisión en 1796. Saldrá hacia el exilio, seis años más tarde, merced a un indulto real, pero con el compromiso de no regresar jamás a España. En 1810 murió en su tierra natal el protagonista de la más importante expedición española del siglo XVIII.

Vid. HIGUERAS, M. ${ }^{\text {a }}$ Dolores: Catálogo crítico de los documentos de la Expedición Malaspina del Museo Naval de Madrid. Madrid, 1985, 3 vls.

Vid. FERRO, Gaetano (ed.): Alessandro Malaspina nella geografia del suo tempo. Genova, 1987.

Vid. GREPPI, Emmanuel, "Un italiano alla Corte di Spagna nel secolo XVIII. Alessandro Malaspina", en: Nuova Antología. Sec. Serie XXXVIII vol. II. 1883.

Vid. MANFREDI, Darío: Alessandro Malaspina dei Marchesi di Mulazzo. Le inclinazioni scientifiche e riformatrici. Lunigiana, 1984. 
Más tarde, y por Real Orden del 29 de febrero de 1792, el Gobierno español decidió conservar Nutka al difundirse la noticia en París de que el descubrimiento de Ferrer Maldonado, a fines del siglo XVI, sobre un supuesto paso entre el Atlántico y el Pacífico, era una realidad. El gobierno de Madrid aprovechó la presencia en la zona de la expedición científico-política mandada por Alejandro Malaspina (29) para encarecerle la verificación del descubrimiento.

La cuestión de Nutka fue resuelta por el acuerdo de 11 de enero de 1794, por el que España la devolvía a Inglaterra, que, a su vez, renunciaría, quedando el país indiviso y de libre acceso para ambas potencias (30). A partir de este mismo momento el fin del mundo, ese fin del mundo tan bien descrito por el profesor Bernabeu en sus interesantes trabajos, dejó de ser español.

Antes del citado Acuerdo, aún se proyectó una quinta expedición de colonización è 1789, con la que se cerró un primer ciclo de exploraciones españolas en el noroeste de América (1767-1789) (31).

Los resultados cartográficos de la expedición comandada por Alejandro Malaspina fueron muy notables, lográndose explorar por primera vez amplios sectores de la costa (32).

\section{LA EXPEDICION MALASPINA EN LA COSTA NORTE}

El viaje de Alejandro Malaspina alrededor del mundo (33) experimentó un cambio en la singladura prevista cuando recibió órdenes de Madrid para que iniciara un detallado y amplio reconocimiento de la

Vid. PALAU, Mercedes (ed.): Diario de Viaje de Alejandro Malaspina. 1789 1794. Madrid, 1984.

Vid. SOLER PASCUAL, Emilio. "La Conspiración Malaspina: estado de la cuestión". La Expedición Malaspina (1789-1794). Bicentenario de la salida de Cádiz. Real Academia Hispanoamericana. Cádiz, 1991.

(28) SOLER PASCUAL, Emilio: La Conspiración Malaspina (1795-1796). Instituto GilAlbert. Alicante, 1990.

(29) POLESE, Richard; WEBER, Michael; CUTTER, Donald y PALAU, Mercedes: The Malaspina Expedition. "In the pursuit of the knowledge...". New Mexico, 1977.

(30) MARTINEZ SHAW, Carlos (ed.): El Pacifico español. De Magallanes a Malaspina. Barcelona, 1988.

(31) ENGSTRAND, Iris H. Wilson: Spanish Scientists in the New World: The Eighteenth Century Expeditions. University of Washington Press, 1981.

(32) CANO TRIGO, José María. "Cartografía grabada en la expedición Malaspina". La Expedición Malaspina. (1789-1794). Bicentenario de la salida de Cádiz. Real Academia Hispanoamericana. Cádiz, 1991.

(33) GALBRAITH, Edith C:: "Malaspina's Voyage around the World". California Historial Society Quaterly, 3. 1924. 
costa noroeste de América (34) para tratar de confirmar la noticia que acababa de estallar en Europa: la Academia de Ciencias de París había hecho pública la veracidad de la existencia del paso de Ferrer Maldonado (35), a través del geográfo francés Buanche, que comunicaba el Océano Atlántico y el Pacífico. El interés político y comercial del suceso motivó que se ordenara a Malaspina dirigirse de inmediato a la zona para que, en caso de confirmarse la noticia, tomara posesión de la misma (36). La reestructuración del viaje acogía nuevamente el abandonado proyecto de incursión por el Pacífico Norte americano a la búsqueda del supuesto paso interoceánico, que hubiera revolucionado el modelo político y comercial de la América colonial dieciochesca (37). Las palabras del propio Malaspina no dejan lugar a dudas sobre la importancia de este hallazgo, caso de llegar a confirmarse:

“... Ni imagine alguno que la utilidad de este paso, a lo menos para los extranjeros, no esté ceñido sólo a la navegación de China, sino que pueda comprenderse en aquellas ventajas una comunicación más breve con el mar Pacífico, hacia donde en los siglos venideros la navegación europea será tan numerosa y rica como es ahora mezquina, inútil y aventurada..." (38).

A partir de este nuevo objetivo, se hizo necesario elaborar un nuevo plan de reconocimiento en las observaciones hidrográficas realizadas hasta entonces. Puertos tan importantes como Los Angeles, entre otros, reclamaban un más detallado reconocimiento. A pesar de las expectativas geo-estratégicas abiertas por la intervención de Buanche, las órdenes recibidas no hicieron excesivamente feliz a Malaspina, que ya llevaba un largo retraso en su expedición y había decidido ya la supresión de la exploración de esta región norteña:

(34) VAUGHAN, Thomas; CROWNHART, E.A.P. y PALAU, Mercedes: Voyages of Enlightenment. Malaspina on the Nortbwest Coast. 1791-1792. Oregón, 1977.

(35) El geógrafo francés Buanche había afirmado en una disertación que tuvo lugar en la Academia de Cienoias de París, la existencia de un paso que comunicaba el Océano Atlántico con el Pacífico, basándose en la legitimidad del viaje realizado por el español Ferrer Maldonado en 1588 desde Nueva Inglaterra al mar Pacífico, desembocando hacia el paralelo 60 , según afirmaba una memoria hallada en los archivos del duque del Infantado.

(36) CUTTER, Donald: Spain and the Oregon Coast. Portland, 1975.

(37) GALERA GOMEZ, Andrés. La Ilustración española y el conocimiento del Nuevo Mundo. C.S.I.C. Madrid, 1988.

(38) MALASPINA, Alejandro. "Diario de Viaje de A. Malaspina". Ed. de PALAU, Mercedes. Madrid, 1984. 
“... En el entretanto, las circunstancias que nos rodeaban no podían a menos de trastornar casi enteramente el plan formado para nuestros pasos del año empezado de 1791; pues o bien llegásemos demasiado tarde a Acapulco y San Blas, para poder emprender el viaje oportunamente a la costa noroeste, o el omitir una parte de las costas de Nueva España nos obligase a retroceder después para reconocerlas, siempre el atraso de un año en la totalidad del viaje parecía indispensable, y por la misma razón debíamos precaverle con la anticipación posible..." (39).

A principios de mayo de 1791 las dos corbetas de la expedición Malaspina, la "Atrevida" y la "Descubierta" comenzaron la búsqueda. El mar de Bering (40) fue elegido como punto inicial de la exploración, guiándose por los dibujos del estrecho copiados por Juan Bautista Muñoz en 1781.

A pesar de que el inicio de la reestructurada travesía coincidió, en principio, con malos vientos, la configuración geográfica de la costa coincidía, plenamente, con la descrita por el capitán Cook, por lo que la expedición de Malaspina no encontró mayores dificultades en su travesía. En las proximidades del puerto Mulgrave, en el interior de la bahía del Almirantazgo, se descubrió una ensenada que, quizás sólo muy remotamente, pudiera parecerse a la descrita por Ferrer Maldonado. El reconocimiento sólo sirvió para descubrir un pequeño fondeadero que recibió el sonoro nombre de Bahía del Desengaño. La ensenada fue bautizada con el nombre de Ferrer. En el tiempo pasado en aquella zona, la expedición trabó el primer contacto con los indígenas que, según el propio Malaspina, no mostraron ningún recelo en establecer una relación amistosa y de intercambio comercial. La existencia, entre los enseres de la tribu de hachas, cacerolas, y otros utensilios, era prueba evidente de la estancia en la zona de anteriores expediciones como las de Cook y La Pérouse.

(39) MALASPINA, Alejandro: Viaje científico y potitico a la América Meridional, a las costas del mar Pacífico y a las Islas Marianas y Filipinas verificado en los años de 1789, 90, 91,92,93 y 94 a bordo de las corbetas Descubierta y Atrevida de la Marina Real, mandadas por los capitanes de navio D. Alejandro Malaspina y don José F. Bustamante. Vid. PALAU, Mercedes (ed.): Diario de Viaje de Alejandro Malaspina. Madrid, 1984.

(40) Es el fragmento más septentrional del Océano Pacífico, del que está separado por las islas Aleutianas, puente entre las penínsulas de Alaska y Kamchatka. Debe su nombre, así como el estrecho de Bering, a Vitus Johansen Bering (16801741), navegante danés al servicio de Rusia, descubridor de Alaska. 
La razón había estado del lado de Malaspina ya que las corbetas, que habían tomado rumbo hacia Puerto Mulgrave a la búsqueda del paso de Ferrer Maldonado, se encontraron con una exploración infructuosa, llegando a alcanzar en su derrota hasta el denominado, desde entonces, glaciar de Malaspina, confirmándose la ficción del viaje de Maldonado:

“...A la verdad, cuanto más examinásemos aquellos contornos, la tierra baja que los ciñe por todas partes a la orilla, y la alta, que tenezmente unida sin el abra siquiera de una cañada o de un río mediano termina con una noble y natural arquitectura, por una parte en el monte de San Elías y, por la otra, en el de Buen Tiempo, tanto más debíamos extrañar, o bien el origen de la Memoria de Ferrer Maldonado, o la facilidad con que se le había dado por el señor Buache un ascenso tan público y legítimado: si las tareas nuestras ya descritas (por ser posteriores a las del célebre navegante inglés) no nos dan siquiera la complacencia de poderlas considerar como importantes para el progreso de la Geografía, puedan a lo menos, evitando en lo venidero nuevos discursos sobre la existencia de un paso hacia esos paralelos, no aventurar más en semejantes pesquisas un número no mediano de vidas y de caudales..." (41).

La cuestión parecía así definitivamente resuelta y aunque el viaje, además, tampoco había aportado novedades hidrográficas ni geográficas relevantes, sí dejó zanjada la polémica sobre el paso inter-oceánico y confirmó la exactitud de las cartas marítimas elaboradas por Cook. Como dijo Alejandro Malaspina en su vuelta a España "... todas las noticias del paso del NO. son falsas, especialmente las que proceden del capitán Meares..." (42). Las reflexiones de Malaspina no dejan lugar a dudas:

“... La latitud de 59 $24^{\prime}$ obsrevada al mediodía y diferentes marcaciones hechas a todos los puntos que teníamos a la vista, dieron lugar a una prolija confrontación de nuestras tareas desde el puerto; que pudimos reunir de nuevo a las inmediaciones del

(41) MALASPINA, Alejandro: Op. cit. Vid. PALAU, Mercedes: Diario de Viaje de Alejandro Malaspina. Madrid, 1984.

(42) MALASPINA, Alejandro. Op. cit. Vid. PALAU, Mercedes. Op. cit. 
cabo Buen Tiempo, al fondo de la ensenada o abra de Ferrer, y a la costa que desde este abra sigue hacia el oeste a las faldas del monte San Elías.

Era la navegación que ahora emprendiamos el verdadero objeto del viaje, pues como se dirigiese a la parte de costa comprendida bajo el paralelo de $60^{\circ}$, en ella debiera hallarse precisamente, según las precisiones del señor de Buache, el pretendido paso de Ferrer Maldonado; por nuestra parte, a la verdad, ya no podía subsistir ni la esperanza más remota de la legitimidad de aquella Memoria, pues a todas las reflexiones ocurridas al tiempo de examinarla y que comprenderemos para mejor orden en un capítulo separado, se agregaba ahora la seguridad, no sólo de estar estrechamente unida toda la cordillera que desde el cabo de Buen Tiempo sigue hasta el monte de San Elías, si también de estarle antepuesta y saliente al mar una faja de tierra baja que de ningún modo indicaba el navegante Maldonado. Al oeste del monte San Elías no pudieran tampoco verificarse jamás sus narraciones, cuando era una precisa circunstancia de las tierras inmediatas al canal, que toda la costa del oeste fuese sumamente alta e impenetrable, y muy lozana y muy capaz de toda siembra la del este.

Sin embargo, aquel trozo de costa no había sido hasta entonces prolijamente reconocidos ni por nuestros navegantes, ni por el capitán Cook, ni por los capitanes Portlock y Dixon, y, por consiguiente, resultaría de nuestras tareas una ventaja no mediana a la Hidrografía, aunque malográsemos el intento primitivo del descubrimiento de un paso desde el mar Pacífico al Atlántico: así, pareció conveniente emprenderlo con la posible exactitud, cualesquiera fuesen los sacrificio del tiempo que hubiese de costar en los meses restantes del verano..." (43).

Tras su fallida exploración, y después de fijar en los mapas las islas de Montagú e Hinojosa, Malaspina tomó rumbo hacia el archipiélago de Nutka; al mando de este establecimiento militar se encontraba el alférez de navío Manuel Saavedra, bajo cuya jurisdicción se encontraba la fragata "Concepción", adscrita a la guarnición de San Blas, y una tropa de auxilio. Malaspina cuenta así su viaje hacia Nutka:

(43) MALASPINA, Alejandro: Op. cit. Vid. PAlAU, Mercedes: Diario de Viaje de Alejandro Malaspina. Madrid, 1984. 
"... a esta hora se dejaron apercibir algunas ventolinas del norte, las que declinando poco después al nordeste parecían convidarnos tan solamente a navegar algo más desatracados, pero no a cesar de la empresa de continuar el reconocimiento de la costa hasta Nutka, de modo que los navegantes venideros no nos tachasen de omisos en un punto tan inmediato a los objetos esenciales del viaje. A la verdad, supuesta de nuestra parte una necesidad de visitar el nuevo establecimiento de Nutka y uno u otro puerto de nuestra California, y de no diferir de la mitad de octubre la llegada a los puertos de San Blas y Acapulco, el reconocimiento de la parte interior del estrecho de la Reina Carlota no pudiera ser tan prolijo que describiese toda la costa, particularmente si como parecía probable ésta fuese más bien formada de islas que de tierra firme o contigua; pero a lo menos se aseguraría la navegación y se dirigirían con más acierto las pesquisas venideras, si tuviesen por objeto el perfeccionar la hidrografía de aquella parte del globo..." (44).

Alejandro Malaspina, el 13 de agosto de 1791, divisa el establecimiento de Nutka y se apresta a realizar escala:

"... A las cinco de la tarde no distábamos más que unas dos leguas de la boca del puerto, cuyo extremo sur nos demoraba al nordeste; ceñimos hasta este rumbo las pocas ventolinas variables que aún dejaban apercibirse, y largamos las insignias con la esperanza de que en el establecimiento inmediato las viesen y supiesen nuestra proximidad. Puede imaginarse cuál sensación nos haría el ver poco después tremolar la bandera nacional en un altito inmediato a la punta sur, y entre los árboles distinguirse los tres palos de una embarcación desaparejada: no ignorábamos de antemano la existencia de un establecimiento nuestro en estas costas; no ignorábamos cuántos caudales se habían derramado y cuánta sangre pudo haberse esparcido para sostener su posición legítima..." (45).

(44) MALASPINA, Alejandro: Op. cit. Vid. PALAU, Mercedes: Diario de Viaje de Alejandro Malaspina. Madrid, 1984.

(45) MALASPINA, Alejandro: Op. cit. Vid. PALAU, Mercedes: Diario de Viaje de Alejandro Malaspina. Madrid, 1984. 
Malaspina, antes de retornar hacia Monterrey (46) pasa unos días en el establecimiento de Nutka que aprovecha para hacer un reconocimiento de los alrededores y estrechar relaciones con los nativos de la zona (47). Es interesante la descripción que del lugar de Nutka encontramos en su Diario de Viaje:

"... estaba al cargo de aquel oficial [el alférez de navío, don Manuel Saavedra, comandante de la fragata "Concepción"] todo el establecimiento comprendidas las baterías; y como se hubiese embarcado, en clase de auxiliar la compañía suelta de voluntarios de Cataluña, hallábase allí al mismo tiempo su capitán, don Pedro Alberni, 'retirados ya en clase de enfermos el teniente y alférez que le habían acompañado. Todos los enfermos, la mayor parte escorbúticos y en muy mal estado, se habían restituido a San Blas en la fragata "Princesa" a las órdenes del teniente de navío don Jacinto Caamaño. El establecimiento había recibido los auxilios necesarios con el paquebote "San Carlos" y la fragata "Aránzazu", y el regreso de esta última desde el puerto de Monterrey a donde se había despachado en busca de carnes frescas, debía con un socorro tan importante asegurar para el próximo invierno el bienestar de la marinería y tropa existente entonces en el presidio. Veíanse en el fondo del puerto diferentes barracas construidas con tablazón; vigilaban para su custodia y buen orden, el mismo Alberni con la tropa acuartelada en tierra; la fábrica del pan fres$\mathrm{co}$, que se suministraba diariamente a todos, el cultivo de las huertas, en las cuales la naturaleza ya prodigaba sus dones, el cuidado de los víveres y pertrechos contra un enjambre harto destructivo de ratas, las herrerías, la misma continuación o incremento de las casas con el corte necesario de maderas, eran otras tantas ocupaciones en las cuales brillaban con igual tesón la subordinación y constancia de los súbditos y el buen ejemplo y acierto de los oficiales comandantes Elisa, Saavedra y Alberni, influyendo últimamente en la conservación de la salud y en la buena armonía que a la sazón reinaba entre todos" (48).

(46) BEERMAN, Eric: "Malaspina in Monterey in 1791", en: A Quaterly Bulletin of Historic Monterey Issued by the Monterey History and Ant Association. Monterey, 1978.

(47) CUTTER, Donald: Spanish Cientific Exploration along the Pacific Coast. Santa Fe, 1963.

(48) MALASPINA, Alejandro. Op. cit. Vid. PALAU, Mercedes. Op. cit. 
Pronto situaron un observatorio en las proximidades de las barracas, iniciándose así las tareas hidrográficas:

"No diferimos un momento en establecer el observatorio en sitio oportuno y no distante de las barracas. Examinóse el paraje de la aguada, y don Felipe Bauzá emprendió sus marcaciones desde el castillo, ya que la tarde placentera y serena proporcionaba la vista de muchos objetos distantes, entre los cuales sobresalía, muy mucho, un pico interno bien notable para el reconocimiento del puerto. Continuaron luego estas operaciones, medida una base para la exacta determinación del puerto, multiplicadas las marcaciones en algunas de las islas del archipiélago interno y sujetado el todo a otros tantos azimutes para que no influyese en la exactitud de nuestros trabajos la mucha variedad de las declinaciones magnéticas que había advertido el capitán Cook. Ultimamente se emprendió al reemplazo de la aguada con las lanchas y bombos, las cuales, como debiesen separarse una legua, aprovechar las mareas y no enturbiar la buena armonía con los naturales, se pusieron siempre al cargo de un oficial acompañado de dos soldados armados" (49).

Al principio de su estancia, no les resultó sencillo entablar relaciones amistosas con unos desconfiados indígenas que se mostraban tímidos y precavidos:

"Varias causas (cuyo origen es extraño para esta narración) influían entonces a que hubiese de parte de los naturales una conducta tímida y precavida con el establecimiento nuestro. Eran pocos los pescadores que veíamos concurrir a las corbetas, y por cuanto deseásemos conocer los diferentes caciques o Taquis, a los tres días de nuestra llegada aún no habían aparecido alguno, sin embargo, que varios dones a las canoas y no pocas promesas a los que nos visitasen debían ser incentivos harto fuertes para atraerlos" (50).

Desde su llegada, los expedicionarios habían agasajado a los pocos nativos que se habían acercado, con sus canoas, a los navíos españoles, pero estos contactos aún no habían fructificado. Era nece-

(49) MALASPINA, Alejandro. Op. cit. Vid. PALAU, Mercedes. Op. cit.

(50) MALASPINA, Alejandro. Op. cit. Vid. PALAU, Mercedes. Op. cit. 
sario que el poderoso cacique Macuina, al que estaban subordinados unos cuatro mil individuos, diera el "placet" (51). Según cuenta Malaspina la estrategia obtuvo, al fin, los resultados deseados:

"Finalmente, en la mañana del 14, el cacique secundario Tlupananuc venció esta barrera, confiado a la verdad en la amistad constante que había reinado entre él y los nuestros; y, sin embargo, tímido y casi asombrado a la vista de tantas fuerzas unidas, se le regaló por nuestra parte abundantemente, se le prometieron dones aún mucho mayores si nos visitase de nuevo con su canoa grande, bien esquifada, y dispuesta a verificar varias evoluciones así de guerra como de alegría. Y con estos incentivos no tardaron en seguirle varios otros, o subalternos o parientes de Macuina, jefe principal de toda la comarca. Nos ponderaba a veces o la extensión de sus dominios, o la solidez de su autoridad; otras veces, sin embargo, con diferentes pretextos y disculpas daban a entender que aquel jefe temía visitarnos..." (52).

El archipiélago de Nutka presentaba una distribución hidrográfica compuesta por varios canales que seguían diferentes rumbos hacia el interior terminando en pequeñas ensenadas donde poblaban los indígenas. Malaspina, al amparo de la confianza generada entre los nativos, pudo no sólö 'réconocer los territorios habitados por ellos, sino penetrar en su entorno y cultura:

"... luego „que se concluyó la aguada pareció un deber esencial de nuestro destino al reconocer los canales internos del archipiélago en el cual nos hallábamos; pudiera aquel reconocimiento ser útil a la sazón para eliminar la cuestión de dominios sobre aquellos parajes, agitada con tanto vigor en Europa; nos dejaría lugar para estudiar las costumbres de los habitantes con algún despacio, ya que los diferentes viajeros que nos habían precedido habían discrepado tanto en describirlas; finalmente, nos sería fácil el atender a las diferentes urgencias del establecimiento para que no careciese de cosa alguna en el invierno próximo aún cuando no regresase la fragata de Monterrey..." (53).

(51) CUTTER, Donald. "Malaspina at Yakutat bay... encounters between the Spaniards and the Indians in 1791". Alaska Journal, n.. 2. Anchorage, 1972.

(52) MALASPINA, Alejandro. Op. cit. Vid. PALAU, Mercedes. Op. cit.

(53) MALASPINA, Alejandro. Op. cit. Vid. PALAU, Mercedes. Op. cit. 
La estancia de la expedición en Nutka sirvió no sólo para dar descanso a la tripulación y la reparación de las corbetas, sino para socorrer al destacamento militar que allí se encontraba próximo a perecer víctima del escorbuto, al no hacerse efectivos los auxilios demandados a Monterrey:

"... Las atenciones nuestras en cuanto al bienestar del establecimiento debieron ser al mismo tiempo bien varias e importantes. Cediéronsele una parte considerable de nuestros víveres, vestuario, tabaco, medicamentos y jarcias; se compusieron las armas y los utensilios de labranza y se les enseñó con mucha utilidad el método de hacer la cerveza con la hoja del pino, que llamaremos, con los franceses, sapineta. A la verdad, no era ésta sino una corta retribución de la generosidad, que la tropa y marinería del destacamento desplegaron hacia nuestras gentes, franqueándoles cuantas verduras pudiesen suministrar las huertas; y brindándose a cuantas fatigas les ocurrían diariamente, si podían llamarse tales o las diferentes atenciones del servicio, o un corte metódico de leña, en el cual alternaban para su mejor conservación la tropa y marinería de ambas corbetas. En un paraje tan abundante de buenas arboladuras, hubiéramos sido, por otra parte, reprensibles si no repusiésemos las piezas rotas en el viaje anterior, lo cual suministró una nueva ocupación útil a una parte de la marinería y a nuestros carpinteros. Así, corrían rápidamente los días, y además de conservarse en buen estado la robustez de todos, veíamos que no eran absolutamente infructuosos los pasos de las corbetas sobre aquellas costas, aun después de haberse frustrado el objeto primitivo del descubrimiento de un paso del mar Pacífico al Atlántico..." (54).

Los nutkeños se dividían en dos clases, los "Tahis", o clase principal, constituida por los caciques y sus descendientes, y los "Mischimi", o clase plebeya, y que la constituían el resto de miembros de la tribu. La relación de los expedicionarios era, lógicamente, con la clase dirigente, los "Tahis", cuyas costumbres, incluidas, sobre todo, las sexuales, chocaban con la mentalidad de los españoles:

(54) MALASPINA, Alejandro. Op. cit. Vid. PALAU, Mercedes: Diario de Viaje de Alejandro Malaspina. Madrid, 1984. 
"...Nuestro roce pacífico con los naturales había a la sazón echado raíces mucho más sólidas, si bien a costa de varios regalos que pedían indistintamente los jefes y los súbditos, además de una continua contribución de galleta. Ya no huían las canoas a la vista de nuestras embarcaciones menores, nos rodeaban diariamente los pescadores con muchas y excelentes calidades de pescados; algunos naturales hacían noche al lado del observatorio; eran pocos los jefes que no nos hubieran visitado, y habíamos merecido igual atención a Mạcuina, si bien manifestase en su rostro mucha desconfianza y no permitiese subir a bordo' a tres mujeres suyas que le acompañaban; no olvidé tampoco en aquella ocasión su interés propio con la venta de una niña esclava que traía consigo. Los oficiales de la fragata "Concepción" solían adquirirlas o con dos fusiles o con una o dos planchas de cobre: Esta especie de cambios, demasiado ligada con las ideas de religión, de moral y de política para poderse discutir en pocos renglones, era a la sazón bastante introducida en nuestro establecimiento y se contaban unos 22 niños de ambos sexos que, o se habían transportado a San Blas o estaban próximos a transportarse, confiados para su educación y manutención venidera a uno u otro individuo de los buques de S.M., siempre elegido entre los que agregase a una buena conducta el hallarse casados en el departamento..." (55).

Las exploraciones realizadas en los alrededores de Nutka despejaron, de inmediato, la insularidad de la zona y así constó en la cartografía realizada por la expedición Malaspina:

"... El mediodía del 25 regresaron ambas lanchas con la mayor felicidad; venían del mar en fuera, pues que sus reconocimientos las habían conducido por un canal interno hasta el puerto de la Esperanza, paraje en cuyas inmediaciones estuvieron las corbetas en la mañanita del 12, y eran fruto de una útil excursión, no sólo el plano exacto de aquel puerto, si también un conocimiento prolijo de todos los canales internos, por manera que ni quedase ya duda de ser una isla el terreno disputado hasta entonces como parte del continente, ni dejasen de adquirirse cuantas nociones eran necesarias para juzgar con rectitud de las circunstancias y de la utilidad de aquel puerto..." (56).

(55) MALASPINA, Alejandro. Op. cit. Vid. PALAU, Mercedes. Op. cit.

(56) MALASPINA, Alejandro. Op. cit. Vid. PALAU, Mercedes. Op. cit. 
Al mismo tiempo que las investigaciones hidrográficas, las relaciones con Macuina y sus nativos habían producido un conocimiento importante sobre los usos y costumbres de los nutkeños, al igual que el intercambio comercial les había proporcionado unos materiales etnológicos de primera magnitud y que después formarían parte de la espléndida colección recogida por la expedición Malaspina:

"...Macuina se había vuelto mucho más afable y humano, pues podía no dudar de las intenciones pacíficas de nuestros oficiales; los condujo a ver su tesoro de barras de cobre, los acompañó después en un corto paseo que dieron al frente de las casas...

... Bien examinado por los señores Espinosa y Cevallos el número de habitantes que existían en los contornos, y formaban, digámoslo así, la sociedad subordinada a Macuina, le supusieron próximamente de 4.000 , constituidos la mayor parte a vivir de una pesca no muy abundante, y alternando su morada según aquella necesidad, en el verano hacia la orilla del mar, y en el invierno hacia los canales internos. Agregaron también a esos conocimientos el examen del suelo y de la vegetación, la colocación geodésica de varios montes internos y, finalmente, la visita de un cementerio en una isla desierta, todos datos que nos proporcionarían idea cabal de aquellos contornos...

...los dos hermanos Natzape y Nanikius, jóvenes de un talento, comprensión y afabilidad singulares, nos suministraron tales ideas, tan claras y tan extrañas sobre su religión, origen, leyes, costumbres, sistema gubernativo, comercio y geografía interna, que nos parecía una ilusión el comprendernos recíprocamente con tanta velocidad...

...Macuina tomó algunas tazas de té a bordo de la "Atrevida", costumbre que se hallaba bien introducida entre sus parientes y jefes subalternos... finalmente, encareció con colores bien vivos y nobles su actual situación, que precisándole a vivir a alguna distancia del mar, le hacía carecer del alimento y le tenía tanto más débil y extenuado, cuanto mayores habían sido anteriormente sus fuerzas y su destreza, hasta el punto de atacar sólo una ballena para arponearla. Dos velas para canoa, cuatro cristales de ventana, una plancha de cobre, algunas varas de paño azul y pocas piezas de quincallería, fueron luego los regalos que se le dieron en la "Descubierta". Ratificó en aquella ocasión la cesión del terreno que había hecho anteriormente para el actual estableci- 
miento nacional; nos aseguró que habría entre unos y otros una paz duradera..." (57).

Terminada su tarea de investigación hidrográfica y antropológica, Malaspina anotó cuidadosamente toda la descripción del viaje de regreso en su Diario y se dirigió a la bahía de Monterrey, desde donde esperaba, pronto, retomar su expedición inicial:

“... La costa que seguía al sur del puerto de Nutka hasta unirse a la de California ya podía considerarse para la oportuna dirección de nuestras tareas bajo un semblante bien diferente al con que debíamos mirar las costas más septentrionales...

... Navegábamos en el entretanto a no mucha distancia de las islas que desde la punta de San Esteban conducen hasta la entrada del estrecho de Fuca. Vióse entre ellas antes a la vela y después fondeado al abrigo de las isletas más foranas una fragata mercante de los Estados Unidos de la América, ocupada sin duda en el tráfico de las pieles de nutria para conducirlas a Cantón...

... Delante de los cabos Perpettua y Flattery del capitán Cook debíamos admirar de nuevo la exactitud de las descripciones de aquel navegante...

... Ya nuestra navegación hasta la punta Reyes, en las inmediaciones del puerto de San Francisco, debió por naturaleza ser bastante acelerada. Corren allí los vientos constantes del noroeste; las aguas toman por la misma razón una dirección permanente al sur; son las costas acantiladas y la sonda extendida hasta unas cinco leguas mar en fuera, pero rara vez se disipa la neblina y esto hace que haya un peligro verdadero para el navegante cuando intenta fondear en el puerto de San Francisco o en el de Monterrey..." (58).

Después de su interesante estancia en Nutka, Malaspina continúa su periplo descendiendo en latitud hacia Acapulco, haciendo estancia en Monterrey (59), donde llegó el 13 de septiembre de 1791. El establecimiento de Monterrey estaba constituido por un presidio que era,

(57) MALASPINA, Alejandro. Op. cit. Vid. PALAU, Mercedes. Op. cit.

(58) MALASPINA, Alejandro. Op. cit. Vid: PALAU, Mercedes: Diario de Viaje de Alejandro Malaspina. Madrid, 1984.

(59) WAGNER, Henry Raup, "Four Early Sketches of Monterey Scenes", en: California Historical Society Quaterly. Vol. 15. 1936. 
a su vez, residencia del gobernador de la provincia y que tenía una guarnición de sesenta y tres hombres con sus respectivas familias. Apenas a dos leguas de distancia se encontraba la misión franciscana de San Carlos del Carmelo que ejercía su influencia sobre un importante número de índigenas.

Habiendo reconocido, por última vez, las costas de California (60) y Nueva España (61), de las que consiguió unas espléndidas descripciones científicas y artísticas (62), antes de llegar a Monterrey, Malaspina, tras reunir las dos corbetas en Acapulco (63), continuó su itinerario hacia las Islas Marianas (64) e Islas Filipinas, narración a la que dedicó tres capítulos en su Diario de Viaje; como allí podemos leer, realizó múltiples expediciones de observación y reconocimiento (65). Su estancia en tierras australianas, adonde acude para observar un diferente modelo de colonialismo "a la inglesa", del cual era tan ferviente partidario (66); su partida de Fort Jackson (67) hacia Vavao y Tonga (68) y su llegada al Perú (69) y, posteriormente, a Chile (70), marcan el final de su periplo por el Pacífico.

La navegación de Malaspina desde Chile a Montevideo y su reconocimiento de las Tierras del Fuego y de la isla de Diego Ramírez, así como sus escalas en las Islas Malvinas y las observaciones efectuadas

(60) CUTTER, Donald: Malaspina in California. San Francisco, 1960.

(61) GONZALEZ CLAVERAN, Virginia: La expedición Malaspina en Nueva España (1789-1794). Mexico, 1988.

(62) BEDDALL, Bárbara G. "Scientific books and instruments for an eighteencentury voyage around the world: Antonio Pineda and the Malaspina Expedition", en: Archivos of Natural History. 1979.

(63) GONZALEZ CLAVERAN, Virginia: Malaspina en Acapulco. Madrid, 1989.

(64) KELLY, Celsus. Calendar of Documents. Spanish Voyages in the Soouth Pacific from Alvaro de Mendana to Alejandro Malaspina (1564)-1794). Franciscan Historical Studies (Australia) in association with Archivo Ibero-Americano (Madrid). Madrid, 1965.

(65) MADULID, Domingo, "Malaspina: Explorer for the science", en: Filipinas Journal of Science and Culture. vol. I. 1981.

(66) SOLER PASCUAL, Emilio, "Oposición política en la España de Carlos IV", en: Revista de Historia Moderna. Anales de la Universidad de ALicante. n. $8-9$. Alicante 1988-90.

(67) GROVE DAY, A. y otros: The Spanish at Fort Jackson. The visit of the comettes "Descubierta" y "Atrevida". Sidney, 1967.

(68) CARRIL, Bonifacio del: La expedición Malaspina en los mares del Sur. Buenos Aires, 1961.

(69) HAENKE, Tadeo: Descripción del Perí. Lima, 1901.

(70) GARCIA SOTOCA, M. a del Carmen: Alejandro Malaspina en Chile. Tesis doctoral de la Facultad de Filosofía y Letras, sección de Historia de América, de Madrid, Madrid, 1964. 
en la costa patagónica (71), marcan el principio del fin de un viaje que, con salida de Montevideo, culmina en Cádiz, tras cinco años de aventura científico-política, un veintiuno de septiembre de 1794.

Independientemente de la amplitud de los resultados, Malaspina en sus confidencias epistolares a su amigo Greppi (72), demostró un interés primordial por el hombre y sus necesidades más que por el conocimiento de la Naturaleza. La lectura de su "Diario de Viaje", así como de gran parte de su correspondencia (73), evidencia que la impresión que le produjo la realidad americana acentuó su convicción de procurar un cambio que mejorase las condiciones sociales. Cambio que, de acuerdo con los presupuestos del momento, sólo sería posible mediante la adecuación de las formas de gobierno y la reforma de la legislación respecto a los territorios americanos. En este sentido escribía Malaspina el 27 de abril de 1791 desde Acapulco:

“... Espero poder servir al Ministerio si quiere tratar de un sistema general sobre principios sólidos y duraderos. El comercio, la defensa y la legislación de América jamás podrán entenderse a fondo mientras no se recorran, como acabo de hacer, sus principales establecimientos sin preocupciones de imitaciones, intereses o reglas fijas..." (74).

Malaspina çonsideraba fundamental eliminar los obstáculos al comercio establecidos por la política monopolista aplicada secularmente por los españoles y que se manifestaba por la implantación de compartimentos estancos que prohibían el comercio interregional. Las tibias medidas liberalizadoras de 1765 y 1778 todavian resultaban muy insuficientes. Lo paradójico del caso es que la Corona española gastó una verdadera fortuna de la época, para sufragar una expedición de la que se extrajeron conclusiones que chocaban frontalmente con los intereses de una metrópoli cuya capacidad de extracción de recursos se basaba en la dominación política y el férreo control mercantil (75).

(71) HAENKE, Tadeo: Viaje por el Virreinato del Río de la Plata. Buenos Aires, 1943.

(72) MALASPINA, Alejandro. Copia de su correspondencia. Real Academia de la Historia de Madrid. Existe un legado de 26 cartas, copia autógrafa en diferentes idiomas, casi todas a su amigo Paolo Greppi y que abarcan el período 1789-1803.

Esta correspondencia consta en el Diario de Viaje de Malaspina, edición que ha preparado la doctora Mercedes Palau y con la que han colaborado estrechamente las profesoras Aránzazu Zabala y Blanca Sáez.

(73) MORSE, William (Ed.). Letters of Alejandro Malaspina (1790-1791). Boston, 1944.

(74) MALASPINA, Alejandro. Op. cit. Vid. PALAU, Mercedes. Op. Cit.

(75) SOLER PASCUAL, Emilio. La conspiración Malaspina. Op. cit. 